\title{
Tesituras encontradas canon y musicología en M éxico o tres reflexiones sobre un juego de estampas
}

\section{Canon y musicología}

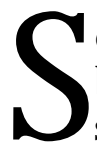

on dieciséis. Son el can on musical de M éxico. Todos usan saco y corbata, todos están bien peinados y todos parecen gente muy decente y sensata. Son los músicos mexicanos escogidos de acuerdo con quién sabe cuál criterio - si es que de verdad hay alguna razón tras la nómina- para conformar la selección nacional, el conjunto que se vende como el mínimo panteón indispensable a los jóvenes de nuestras escuelas primarias, secundarias, preparatorias quizá, y que cumplen una legendaria y arcaica función: la de ser estampitas para la tarea, esas sui generis fuentes documentales que sacan del atolladero a cualquier párvulo, y que con un poco de pegamento sirven además para ahorrarse la elaboración de las ilustraciones en la tarea.

Impresa por Ediciones Raf, la colección de estampitas a la que hago referencia es reveladora en muchos sentidos. Para empezar, es una "joya" de la iconografía musical mexicana pues pinta imágenes insospechadas de nuestros músicos. Revueltas, por ejemplo, aparece con una cabellera rizada y alzada, digna de algún roquero afroamericano. Luis Sandi tiene una expresión francamente cómica, con la mirada vuelta hacia arriba, como si quisiera acordarse en qué lugar quedó perdida (¿por siempre?) la afinación de su Coro de M adrigalistas, y sólo Carrillo, entre todo el conjunto, dirige su mirada hacia nosotros, como si escuchase tras nuestra presencia algún sonidito que se le ha escapado. Blas $\mathrm{G}$ alindo exhibe una cara tan regordeta que apenas se le reco- 
noce y, en cambio, M acedonio Alcalá muestra una imagen más bien depresiva. Por alguna razón desconocida, quizá porque Dios nunca muere y los oaxaqueños sí, es, junto con Bernal Jiménez, el más apesadumbrado del conjunto. En cambio, en otras expresiones no hay sorpresa: Elorduy es el que más sonríe y Chávez es el que más dura expresión denota; Ponce mira hacia la derecha, Chávez hacia la izquierda, y uno se pregunta si en lugar de una coincidencia fortuita hay en ello alguna evidencia ideológica que los anónimos dibujantes conocen. Pero no sólo los gestos sino también los atuendos son reveladores. Lerdo de Tejada, Bernal Jiménez, Ponce, Codina y Rosas utilizan todos corbata de moño, sin duda por alguna razón - también ignorada por nosotros- que al parecer la sensibilidad de los dibujantes de Ediciones Raf percibe como rasgo común de la música de estos autores, y que futuras generaciones de musicólogos habrán de escudriñar.

Sin embargo, lo más notable de tal colección es el hecho de que dichas estampas reflejan a su manera una tarea central del quehacer musicológico, quees la conformación del canon. Se trata, desde luego, de una parodia; pero por ello mismo esas estampas constituyen un penoso testimonio del impacto que la investigación musical en M éxico ha tenido más allá de sus ámbitos institucionales. Como no existe un canon de la música mexicana establecido con cierta claridad, y en tanto el trabajo de investigación musicológica adolece de problemas de método, difusión y recursos, quienes hacen las estampitas - y lo quees peor, quienes las consumen y reproducen - seguirán imaginando cualquier cosa.

La construcción del canon ha sido concebida y analizada como una tarea central de la musicología. N o se trata, desde luego, de producir una simple lista de nombresilustres, sino de forjar un razonamiento crítico que señale los méritos y val ores de las distintas obras del repertorio clásico. Se trata de una noción debatida, cuestionada y examinada por los principales teóricos de la musicología, pero, a pesar de su uso y abuso, no parece existir en la disciplina musicológica contemporánea mayor divergencia respecto a dos puntos centrales. Primero, el canon define las obras intelectualmente y desde una perspectiva crítica; segundo, la construcción de ese canon ha sido entendida como una labor central de la musicología. "Crear cánones y sostenerlos ha sido una tarea normativa para los musicólogos", resume Philipp V. Bohlman al examinar este asunto. ${ }^{1}$

1. "C reating canons and buttressing them is indeed a normative task for musicologists", Philipp Bohlman, "Epilogue: M usics and Canons", en Katerine Bergeron y Philipp Bohlman (eds.), D isciplining M usic, M usicology and its Canons, Chicago University Press, 1992, p. 201. 
1. Estampas de M iguel Lerdo de Tejada, Agustín Lara, Blas Galindo y José Rolón.

Ediciones Raf.

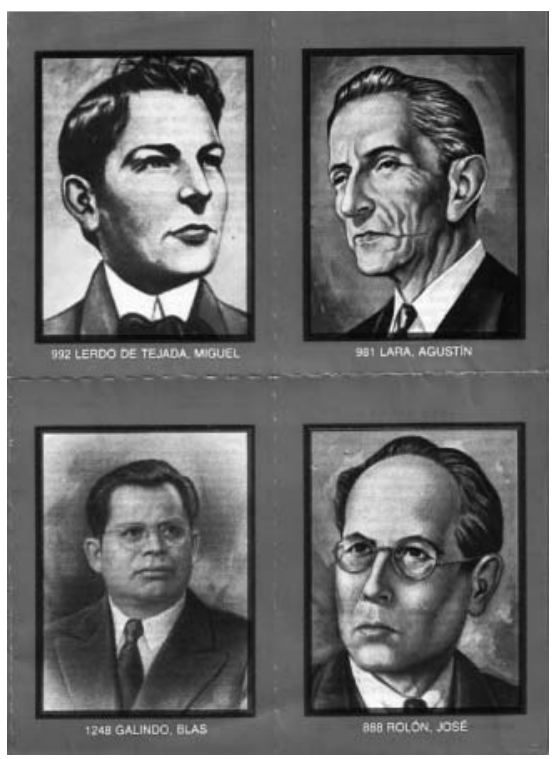

Pero no en M éxico. M ientras que los más importantes autores alemanes, italianos o franceses han sido estudiados cabalmente y se conocen y valoran con amplitud, es una tarea pendiente de la musicología mexicana lograr que nuestros músicos relevantes - digamos, al menos, los dieciséis de las estampitas- tengan toda su música editada, grabada y acompañada de estudios críticos. Lejos de tal situación, la investigación musical en M éxico ha discurrido por senderos a cual más diversos y dista mucho de conseguir ese objetivo tan importante: ningún autor mexicano tiene toda su música editada, mucho menos grabada, y sólo algunos cuantos han generado un acervo significativo de estudios críticos. Esa labor, esencial para toda música - sujeta al trabajo colectivo de musicólogos, intérpretes e instituciones-, no ha sido terminada ni del todo sustentada por la musicología mexicana. No existe para nuestra sociedad una noción clara de quiénes son los músicos mexicanos más relevantes ni por qué lo son. A lo sumo, existen una serie de lugares comunes, por lo general erróneos, respecto a ese canon: sólo así se explica que una obra de factura mediana como Sones de mariachi sea más conocida que algunas de las obras maestras de Revueltas o Ponce. Vamos, ni siquiera esa cuestión parece resuelta para músicos de cierta preparación como pudie- 
ran ser la mayoría de los directores de orquesta, quienes ignoran en un grado alarmante la amplitud y alcance del repertorio sinfónico mexicano y se contentan con programar las mismas piezas de siempre, o de añadir, si acaso, algún éxito reciente, como pudiera ser el $D$ anzón número 2 de Arturo $M$ árquez. $\mathrm{Ni}$ la Sinfónica $\mathrm{N}$ acional ni ninguna otra orquesta han hecho suya una política permanente de interpretación de autores mexicanos ni de rescate 0 restauración de un repertorio que padece la peor de las suertes: el silencio. Aunque han ocurrido algunos intentos, todavía se ve lejano el día en que nuestras orquestas tengan en sus consejos a uno o dos musicólogos que, más que real izar sugerencias, sean capaces de proveer fuentes y materiales para un repertorio renovado. Pero el estancamiento del repertorio sinfónico, lo mismo que la venta de sordas estampitas o de muchos otros ejemplos que pudieran ofrecerse, es revelador de la carencia de un parámetro que permita definir a cuál música deben destinarse recursos y effuerzos, cuáles son las obras importantes y que merecen difundirse o cuáles los autores que requieren atención y trabajo por parte de los especialistas.

En buena medida, la ausencia de un canon en nuestra música se debe a la falta de claridad metodológica que distingue a la investigación sobre música realizada en nuestro país. Pudiera, incluso, establecerse una diferencia clara entre musicología e investigación musical, imaginando que se trata de dos áreas afines, de dos voces de tesitura distinta que a veces suelen encontrarse, pero que están separadas por su relación temática o metodológica con el canon. M ientras que toda labor de rescate 0 estudio sobre la música mexicana pudiera considerarse investigación musical de algún tipo, quizá no toda la investigación es necesariamente musicológica en tanto no todas las indagaciones sobre música realizadas en nuestro país señalan las virtudes intrínsecamente musicales de su objeto de estudio. En este sentido, hay un deber ineludible que no todos los llamados investigadores parecen querer o poder cumplir. Si sus trabajos los llevan a un tema determinado - un autor, un repertorio, una institución u otro semejante- , es imprescindible señalar cuáles son los méritos musicales de tal o cual objeto de investigación. Avalados en la supuestamente inexpugnable posición de que toda labor que contribuya al rescate de la música mexicana es buena, la investigación musical en M éxico discurre por los senderos más inverosímiles y extraordinarios y, en una buena cantidad de casos, abandona por entero la música para ocuparse de otras cuestiones que son, gracias a ese mismo abandono, secundarias. 
H asta cierto punto, considerar la construcción del canon como parámetro para distinguir entre investigación y musicología constituye un criterio forzado y no exento de contradicciones. Pero la necesidad de llevar un argumento a extremos tales no es gratuita. El ejercicio de la investigación musical en M éxico es tan accidentado y se encuentra tan plagado de confusiones metodológicas que muchas veces se vuelve necesario hacer excepciones y paréntesis para referirse al tema con cierta precisión. Incluso la simple determinación de lo que constituye un musicólogo puede volverse un asunto espinoso en tanto ciertas definiciones, aceptadas en otros países, aquí se vuelven problemáticas. En Estados U nidos o Alemania, nadie que no ostenta un doctorado en la especialidad se llama a sí mismo musicólogo. En esos países y en otros como Inglaterra, Francia o Polonia, además de los títulos se espera que el musicólogo ejerza una cierta actividad de músico práctico aunada a sus investigaciones, y es poco menos que imposible estudiar musicología sin haber pasado una licenciatura en música. Lo contrario, por ejemplo, ocurre en España, donde ahora mismo se debaten entre la validez de la musicología enseñada en las universidades - fuertemente vinculada con las humanidades, y no necesariamente con una fuerte carga de música práctica- y la forjada desde los conservatorios, con un programa y una experiencia previas muy distintas. ${ }^{2}$ En todos esos países, por lo demás, la tarea del musicólogo va inexorablemente ligada a un ámbito de trabajo universitario, donde la investigación y la enseñanza son actividades permanentes que se retroalimentan. En M éxico, por otra parte, el sustantivo se aplica con una liberalidad inversamente proporcional a la escasez de títulos: son musicólogos quienes escriben sobre música - tengan o no estudios profesionales en la materia, toquen algún instrumento a nivel profesional o sean meros melómanos, enseñen en alguna institución o sólo sean "investigadores"- y en ese costal tan ancho caben lo mismo especialistas de renombre internacional que al gún improvisado autor de notas de concierto o de biografías y estampitas. $\mathrm{H}$ ay, además, distinguidos colegas que no estudiaron musicología pero que son musicólogos de cepa y de facto: sus trabajos y méritos los ubican con facilidad en el gremio musicológico a pesar de la carencia de títulos. Para terminar de complicar la situación, hay quienes sin estudios musicales son capaces de forjar

2. La discusión acerca de la homologación de los grados otorgados en España surge a partir de las normas de educación superior expedidas por la Comunidad Económica Europea y estipuladas en la convención de Bolonia. 
valiosas contribuciones al terreno de la musicología histórica desde la documentación. Por lo demás, el musicólogo típico descrito anteriormente es en M éxico una rara avis: quienes ostentan un grado en musicología realizan investigación y forman parte de alguna institución universitaria o de enseñanza superior - tres requisitos holgadamente cumplidos por la amplia mayoría de miembros de la International M usicological Society o de la American M usicological Society - son en M éxico una mínima minoría, val ga el pleonasmo.

Estas reflexiones obligan a encontrar un tamiz diferente que permita de finir lo que es el musicólogo mexicano. Pero si atendemos a otro tipo de definiciones, el asunto no parece aclararse. Kerman, por ejemplo, se ha re ferido a los musicólogos populares y académicos, distinguiendo así entre quienes escriben las notas a un programa o disco de quienes desarrollan - propiamente dicha - una musicología crítica y académica. En M éxico tal separación resulta inadmisible, pues de ser aceptada habrían de considerarse entre nuestros colegas todos aquellos improvisados que - sin estudios, sin formación- Ilenan de tonterías los programas de mano de nuestras orquestas, las páginas de múltiples periódicos, no pocos cuadernillos discográficos y varias horas diarias de tiempo radiofónico. Tal consideración nos conduce hacia otros autores como Chailley, cuyo concepto de musicólogo se funda en una consideración metodológica que sólo incluye a quien genera su trabajo a partir de fuentes primarias. Esta útil precisión permite distinguir entre quienes producen ideas y conceptos a partir de investigación original y quienes simplemente reproducen los hallazgos o los textos de otros. Pero aun esta definición que tiene sus virtudes deja fuera un aspecto crucial: la crítica y la reflexión. Porque es posible, después de todo, no recurrir a ninguna fuente primaria y, sin embargo, ejercer un discurso musicológico crítico y novedoso, sobre todo cuando éste posee una vocación hermenéutica. Figuras notables de la musicología como Leo Treitler, Carl Dahlhaus o M aynard Solomon han escrito libros o ensayos memorables en los que no recurren a ninguna fuente primaria.

Tales son las dificultades para definir qué es un musicólogo, dificultades que, al surgir en un entorno como el nuestro, se acentúan, pues los problemas fundamentales de la disciplina se ven aumentados y agudizados por la falta de rigor, por la improvisación, por la inercia institucional y por una carencia absoluta de discusión respecto a qué es la musicología y cuál es su lugar en nuestra sociedad. A ello se debe que un problema tan elemental como el de la metodología surja de inmediato al considerar los trabajos pro- 
2. Estampas de G enaro Codina, M acedonio Alcalá, Silvestre Revueltas y Luis Sandi.

Ediciones Raf.

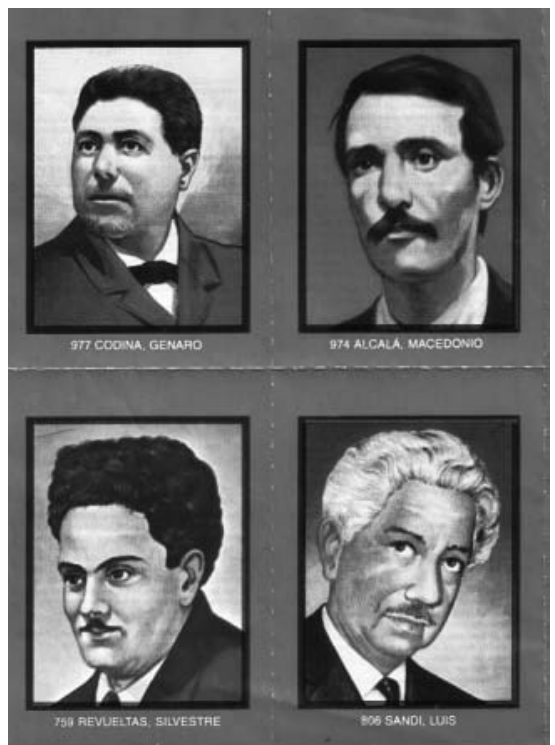

ducidos en M éxico en recientes años. Grosso modo, existen dos grandes posiciones: las de la documentación y la reconstrucción histórica - a cargo de investigadores diversos- , y las de la crítica y la reflexión estética, hechas con criterios musicológicos más o menos claros. Dicha oposición representa un rancio problema de la musicología. En una definición célebre, $C$ arl $D$ ahlhaus afirmó que la historia de la música - objeto disciplinario central del musicólogo - falla como historia cuando se convierte en una secuencia de análisis estructurales de distintos trabajos y falla como historia del arte cuando abandona la obra musical para ocuparse únicamente de las circunstancias históricas o sociales que constituyen la narrativa histórica. ${ }^{3}$ En el caso de la musicología mexicana reciente, esta situación es notablemente aguda: son mínimos aquellos trabajos que no pierden de vista la obra musical - sea en favor del compositor como personaje biográfico, sea incluso en aras de algún rescate filológico- y que nos entregan una visión donde ambos aspectos están presentes o balanceados. Por lo demás, el acervo de análisis es notable-

3. Este asunto fue discutido por $C$ arl $D$ ahlhaus en el capítulo segundo de su Grundlagen der M usikgesichte, Colonia, $\mathrm{H}$ ans G erig, 1977. 
IO2

mente pequeño y parecería que muchos colegas han encontrado más fácil ocuparse de cuestiones meramente documentales que de ofrecernos un discurso a partir del estudio de alguna obra determinada. En suma, se pretende hacer musicología, pero más a partir del trabajo de archivo que de la audición, y, en todo caso, son mayoría los trabajos que ostentan una curiosa metodología que nos conduce de nuevo a las famosas estampas.

\section{La técnica de la estampita}

Aunque las imágenes son memorables, es del otro lado de las estampitas donde se desata el horror. Uno a uno, los dieciséis músicos son sometidos a un mismo tratamiento, a una misma metodología, si se concede un uso generoso del término: al esbozo biográfico con los datos de rigor, le sigue una sorda lista de algunos títulos relevantes - como si lo importante de los músicos fuera saberse los títul os de sus obras y no escucharlas- y una sarta de lugares comunes que, cuando no espantan, son francamente incomprensibles. Revueltas, por ejemplo, tiene un estilo "de gran vigor y originalidad y se distingue sobre todo por la plasticidad sonora" (sic). Julián Carrillo "armó una revolución musical en el mundo" (todos recordamos la D ecena trágica en la ópera de Viena, ¿no es así?). José Rolón fue un "fecundo compositor" (a pesar de poseer un catálogo breve, se entiende). Agustín Lara, cuyas "canciones Ilenaron una época" (sic), fue "un verdadero ídolo popular", etcétera, etcétera. Supongo, con una desesperación imbatible, que tales frases se multiplican como los conejos en cuadernos y tareas realizadas a lo largo y ancho del país. $Y$, encima de todo, debo suponer también que tan estúpidas frases sólo se multiplican en los cuadernos de aquellos "afortunados" a quienes todavía les dejan alguna tarea sobre la música mexicana y sus autores.

Sin embargo, tal parece que la técnica de la estampita prevalece y se multiplica no sólo en las malas escuelas sino en otros ámbitos y niveles. U na revisión de los trabajos musicológicos publicados en M éxico durante los últimos veinte años revela que bajo la forma de diccionarios, historias, libros o artículos, las estampitas proliferan en grandes cantidades y por doquier. M uchos de estos trabajos, considerados desde un punto de vista metodológico, no revelan mayor diferencia en sus partes respecto a las odiosas estampas, salvo en la precisión: la información biográfica puede estar rigurosa y debidamente anotada, los títulos de las obras seguramente vienen acompañados de todos 
los tecnicismos de una ficha de catálogo (dotación, fechas, ediciones, ubicación de manuscritos, etc.) y ciertamente las imágenes inventadas suelen sustituirse por fotografías, pero al fin y al cabo son eso, imágenes que no suenan a nada. Por lo demás, en una gran cantidad de trabajos pueden encontrarse los infaltables lugares comunes que caracterizan a las estampitas de marras. Libros como los de Simón Tapia Colman o Hugo de Grial - por no citar aquel tristemente célebre diccionario elaborado por $\mathrm{G}$ abriel Pareyón, un verdadero arsenal de estampitas que pulula en los anaqueles de nuestras bibliotecas- no son sino pomposas colecciones de fichas un poco más grandes y más elaboradas que no difieren - en método- , sin embargo, de las estampitas escolares y esconden, sin discreción, frases inexplicables y conceptos manoseados que nada o poco aportan.

A pesar de los argumentos esgrimidos por quienes favorecen la escritura de semejantes trabajos, según la falsa premisa de que cualquier trabajo en torno de la música mexicana al go contribuye 0 algo ayuda, sigo sin entender en qué medida permiten escuchar la obra de nuestros compositores. $Y$ es que un aspecto crítico de tal metodología no radica únicamente en el manejo - relajado, riguroso, puntual o fantástico- de datos e información, sino en un contrasentido absoluto: la música no aparece en ellos por ningún lado. Volvamos a las estampas. Cuántos muchachos, me pregunto, no copiarán las referidas fichitas, sacarán alguna buena calificación y, sin embargo, no habrán escuchado una nota del compositor en turno. Imagino con espanto que uno de los potenciales consumidores de las estampitas escribe en su cuaderno que Ponce, "con fuerte influencia del arte alemán, compuso Estrellita". De suyo, es una noción historiográfica horripilante, pero más aún lo es el hecho de que quizá esa joven o ese niño no hayan escuchado una sola de las notas escritas por Ponce. Lo peor de todo esto es que las estampitas multicitadas confunden el árbol con el bosque, e identifican a los músicos, su biografía y su catálogo con el objeto artístico que, en realidad, debiera interesarles. Ahora bien, ¿cuántos trabajos "musicológicos" publicados en M éxico durante los últimos veinte años no adolecen del mismo defecto? Escojo hablar de un periodo de dos décadas por razones significativas y estrictamente historiográficas: fue en 1984 cuando la Universidad Nacional Autónoma de M éxico, mediante el Instituto de Investigaciones Estéticas, publicó la más reciente de nuestras historias de la música. Y basta revisar a ojo de pájaro aquellos volúmenes para darse cuenta del problema que nos ocupa: capítulos enteros - por no decir tomos- pasan de largo sin hablar de la música como fenó- 
meno estético y se contentan con lo de siempre: datos, hechos históricos, nombres de obras, fotografías... lo mismo que en las estampitas. Claro que de ninguna manera pueden compararse con ellas, por su precisión y extensión, los trabajos referidos, informados, documentados y bien escritos; pero también es cierto que no por ello difieren en su metodología de las referidas estampas. Ahora bien, llega a mis manos el más reciente libro sobre música publicado por el Centro $\mathrm{N}$ acional de Investigación e Información M usical Carlos Chávez (cenidim) y lo que me encuentro es algo muy similar: una biografía de Miguel Bernal Jiménez profusa y ampliamente documentada por Lorena D íaz. En este trabajo abundan las evocaciones, los datos, las fotografías y hasta las disquisiciones históricas. Me sirve repasar las páginas de este trabajo para recordar la importancia de Bernal como bastión musical de la derecha en M éxico y para entender las circunstancias biográficas de tal cuestión. Pero para lo que no me sirve este volumen ni el acucioso catálogo publicado por la misma autora es para conocer - estéticamente, se entiende - la música de Bernal Jiménez o para enriquecer mi audición de la misma. No hay en todo el libro - dato revelador - un solo ejemplo musical, y si quien lo adquiere busca encontrar alguna apreciación crítica de la música de ese autor, habrá comprado el texto en vano.

No son los señalados los únicos trabajos que adolecen de tales defectos y me refiero a ellos de manera circunstancial, reacio a emprender una reseña crítica amplia de cualquiera de ellos. Simplemente los menciono porque permiten acotar un espacio temporal e historiográfico preciso, un espacio en el que sobra decir que también hubo numerosas y honrosas excepciones respecto al problema metodológico en cuestión. De hecho, durante los últimos veinte años la musicología en torno a la música mexicana ha podido abandonar sus largas, hondas y honrosas raíces positivistas - forjadas por Romero, Saldívar, Stevenson y tantos otros- para incursionar en terrenos más cercanos a la crítica. Sé perfectamente que hubo en el pasado intentos de una musicología menos positivista y que muchos autores han publicado trabajos acerca de la música mexicana en los que las cuestiones anecdóticas o de información pasaron a un segundo plano. Autores como Salazar, Alcaraz, M ayer-Serra, M oreno Rivas y algunos más supieron escribir acerca de lo esencial y dejaron a otros investigadores y para otros lectores que no eran los suyos la información de las estampitas. H ubo incluso - por increíble que parezcauna época no muy lejana en la que G erónimo Baqueiro Foster se daba el lujo de imprimir ejemplos musicales en su columna de EI Nacional, asumiendo 
3. Estampas de M iguel Bernal Jiménez, Gustavo E. Campa, Julián Carrillo y Felipe Villanueva. Ediciones R af.

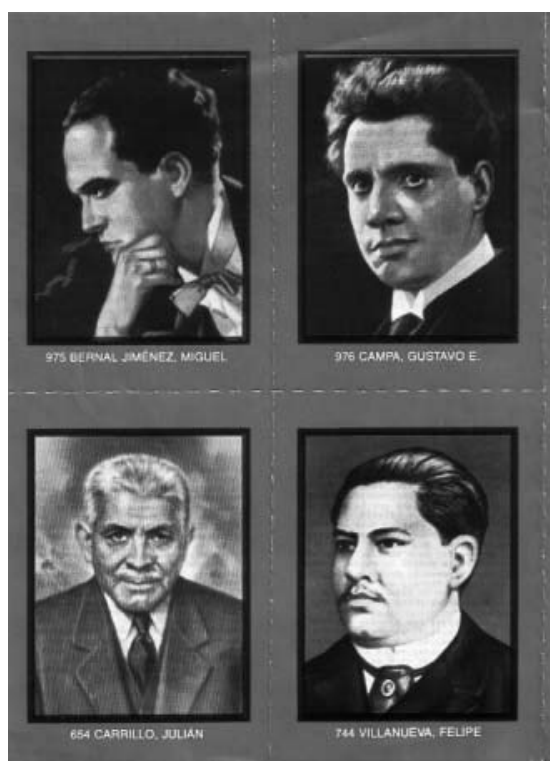

que al menos algunos de entre sus lectores podrían descifrar aquellas pautas y precisar - en términos estéticos- ciertos conceptos por él expuestos. Este mínimo recuento basta para concluir que la oposición entre una musicología positivista y una musicología más crítica - definida con vehemencia por Joseph Kerman desde hace veinte años en un libro célebre $-{ }^{4}$ encuentra en M éxico innumerables ejemplos en ambas tesituras. Y es una característica de la investigación musical actual en nuestro país que esas tesituras coexisten y antagonizan, compitiendo muchas veces por presupuestos y posiciones - plazas, nombramientos, encargos, consejos - todo ello bajo la indefinible sombrilla de una supuesta musicología: todos son musicólogos o, al menos, investigadores sobre música y que cada quien entienda lo que quiera - 0 lo que pueda - en cuanto a tales nombres. Sin embargo, definir la relevancia de un tema de investigación desde la simple justificación personal o eludir

4. Joseph Kerman, Contemplating M usic, Challenges to M usicology, $\mathrm{H}$ arvard U niversity Press, 1983. La edición británica de este libro llevó el título de M usicology y fue descrita por Philipp Brett como "un momento decisivo de la disciplina". Para Kerman, la crítica musicológica equivale a la construcción de significados, con lo cual hace suyas las ideas de Leo Treitler: "una interpretación amplia de lo que una obra de arte significa en todos sus entornos" (Contemplating Music..., p. 132). 
I06

por entero esa cuestión resulta muy cuestionable y suele desembocar, por lo general, en un incremento de estampitas. Pero sucede, además, que la obtención de recursos - becas, plazas, contratos- para producir estampitas es cada vez más debatible cuando ya está frente a nosotros una nueva generación de musicólogos: mejor preparados, debidamente formados, con ideas y proyectos renovadores y que, sin embargo, no tienen cabida en un medio saturado. $M$ ientras los jóvenes se preparan y contemplan con horror el abigarrado espacio académico de la investigación musical en M éxico, muchos de quienes ocupan esos espacios permanecen ajenos a los problemas de la disciplina y siguen produciendo... estampitas. En este sentido, la musicología mexicana semeja una partitura coral pobremente escrita: las voces se cruzan, las tesituras se encuentran y la falta de precisión y alcance de la disciplina se acotan y ensanchan según convenga.

\section{$\mathrm{H}$ acia dos posibles futuros}

De frente a cuestionamientos metodológicos como los aquí esbozados, suele surgir una justificación reiterada: primero es necesario tener al alcance toda la información y documentación de un compositor, después ya vendrá lo demás. Tal argumento es una falacia. Para empezar, la simple elección de cualquier tema es ya una selección crítica y quienes escriben de compositores u obras determinadas ya ejercen un mínimo acto crítico, pero al evitar toda referencia a la cuestión estética se engañan y engañan a sus lectores, pues, en la medida en que el trabajo musicológico se aleja de la música y su apreciación crítica, se vuelve más débil y cuestionable. La defensa en favor de reunir evidencia positivista como condición previa al ejercicio de la crítica fue la que los musicólogos solían invocar en Europa o Estados U nidos hace ya varias décadas y la misma que está detrás de gran parte del trabajo musicológico que se realiza en diversos países. Sin embargo, ni las circunstancias de trabajo ni los logros al canzados por la musicología mexicana permiten trasladar aquí los argumentos surgidos en países de rancia tradición musicológica. Por ejemplo, sería difícil encontrar algo particularmente escandaloso entre los múltiples trabajos positivistas emprendidos en torno a M ozart por especialistas de diversas nacionalidades. Se trata, después de todo, de un compositor cuya música está editada, grabada, difundida, estudiada y se toca en todo momento. Esos requisitos fundamentales han sido cumplidos y el lugar 
4. Estampas de Ernesto Elorduy, M anuel M. Ponce, Juventino Rosas y Carlos C hávez.

Ediciones Raf.

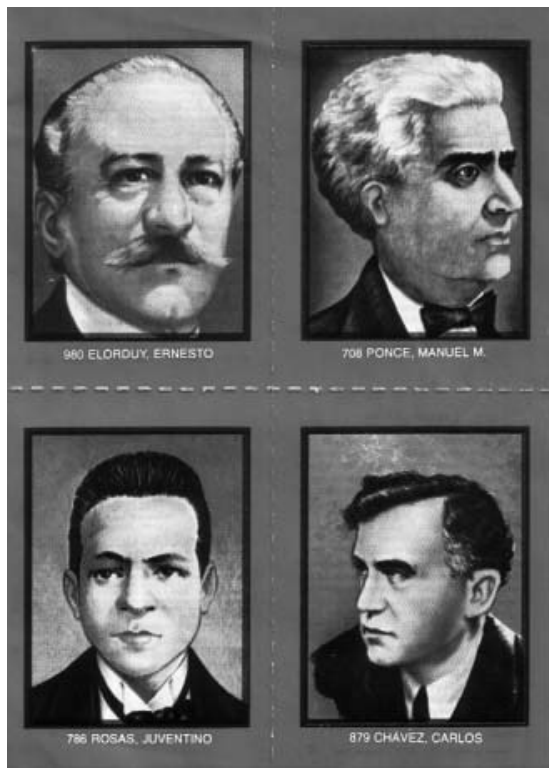

de M ozart en el canon occidental no está en discusión. Pero sería un absurdo mayúsculo dedicarse a reconstruir las circunstancias de la práctica musical en la catedral de Salzburgo o el inventario cronológico de los sellos de agua del papel empleado por el compositor, cuando estuviera pendiente discutir la relevancia del Réquiem K. 626 o cuando Le nozze di Figaro sólo fuese la referencia documental de una ópera sin editarse consignada en un catálogo debidamente impreso por el Centro $\mathrm{N}$ acional de Investigación, D ocumentación elnformación Musical... de Austria.

Pero al escribir la biografía de un compositor mexicano, al hacer el inventario de sus obras 0 al editar sus escritos personales o públicos - todas tareas documentales de cierta relevancia- difícilmente se cumplirá el propósito de comprender y fijar su importancia musical, artística: es necesario indagar y precisar cuál es la relevancia de todos ellos qua músicos, cuáles los méritos estéticos de sus obras, cuáles sus conexiones y relevancia para la historia, pero siempre a partir de la música y su audición. Sólo así podrá la musicología aportar su parte en ese urgente proceso colectivo que nos permita clarificar cuál es esa ilustre nómina canónica de nuestra música. ¿En verdad Blas Galindo es un compositor relevante? ¿M erece la música de Sandi ser rescatada? 
IO8

¿Vamos a dejar al buen Lara junto a Revueltas o Ponce? ¿Cuántos de estos autores deben salir para ceder su lugar a figuras de otros tiempos, a Sumaya, Jerusalem o Gutiérrez de Padilla? ¿Fue C ampa un compositor crucial? ¿Puede serlo ahora? ¿Le basta a Rosas la fama de Sobre las olas para dejar en la banca a José Pablo M oncayo? ¿En verdad son autores esenciales quienes han escrito una página famosa como Alcalá o Codina?

$\mathrm{N}$ o parece haber duda respecto al hecho de que las contradicciones metodológicas que se asoman a nuestra investigación musical pueden leerse como una consecuencia directa de la falta de una precisión canónica y de un sacrificio de la estética en favor de la documentación. Se trata de un círculo vicioso, pues tampoco parece ser un tema debatible asumir que son finalmente los musicólogos - definidos tan amplia o tan estrechamente como se quieraquienes en buena medida van forjando, mediante la crítica y la investigación, la imagen que cada sociedad tiene de la música. Por lo tanto, si la música mexicana llega condensada a las escuelas en absurdas colecciones de dieciséis estampas, ello se debe al pobre lugar que como sociedad le acordamos a la música y al fracaso de la musicología para darles impacto y resonancia a sus tareas. Este problema es todavía peor que aquel de las estampitas, pues refleja, en casos extremos, las dolencias torales del país: el centralismo ha concentrado la investigación musical en la capital y sólo quienes tengan acceso a un presupuesto para viajes 0 viáticos pueden pensar seriamente en investigar música desde la provincia. La corrupción - otro problema del país- se asoma también a la musicología: no son pocos los llamados "investigadores" que tras años y años de cobrar al gún sueldo han producido - en el mejor de los casos- algunos de los libros más caros que jamás ha pagado el erario federal, algunas de las estampitas más onerosas que se han subsidiado con nuestros impuestos. Pero hay otros que de plano no han producido nada y que, tras años y años de cobrar un sueldo y de ocupar una plaza que en justicia no les pertenece, siguen hablando de un eterno proyecto a punto de materializarse. Por otra parte, quienes comienzan a ejercer la musicología en nuestro país, los jóvenes que están terminando su doctorado o que ya lo han hecho y quizá están a la espera de alguna oportunidad de trabajo, requieren especial atención: la música mexicana - entendida como parte fundamental del patrimonio artístico- requiere de su trabajo valioso y especializado. No hay, sin embargo, nuevas plazas ni restricciones de edad o demanda de títulos profesionales para quienes compiten por las ya existentes. Además, la pobreza del país también se refleja en nuestro campo: los recursos para publica- 
ciones son cada vez más escasos y los pocos presupuestos disponibles están injustamente repartidos. Los presupuestos institucionales para la impresión de libros, partituras y discos han sido drásticamente cortados en años recientes y nada permite suponer, de cara al horizonte político actual, que dicha situación habrá de revertirse. Todos estos problemas, lamentablemente, afectan a todo el gremio, lo desprestigian y le restan posibilidades competitivas de frente a otras disciplinas en las humanidades o las ciencias sociales. ${ }^{5}$

Todo ello son razones adicionales para confrontar algunos de los problemas señalados. Es necesario criticar los trabajos musicológicos que se producen y apuntar - al menos- sus carencias metodológicas más evidentes. Es también impostergable destinar recursos humanos y materiales a la consolidación musicológica de la obra de nuestros grandes autores, es necesario que los músicos e instituciones musicales paguen el precio del saber - como dice Richard Taruskin $-{ }^{6}$ y que aprendan lo que no saben o que contraten a musicólogos que puedan forjar nuevas programaciones, ediciones, discos, etc. Asimismo, es necesario que los musicólogos tomemos una mayor conciencia de la dimensión social de nuestro trabajo. Ello implica, como bien apunta Ralph P. Locke, revelar de qué manera los repertorios musicales han sido moldeados por sus funciones y contextos. ${ }^{7}$ Propugnar la construcción del canon no necesariamente implica hacer de la obra musical autónoma un paradigma, y sobra decir que ninguna metodología extrema será provechosa, aunque no está de más recordar aquí la crucial noción propuesta por $\mathrm{H}$ arold Bloom: "sin el canon, dejamos de pensar". 8

¿Serán necesarios veinte años más para poder resolver las cuestiones aquí planteadas? Con un optimismo que no tiene fundamento, quisiéramos creerlo así: que veinte años no es nada... que en veinte años las estampitas serán una reliquia metodológica del pasado; que en veinte años tendremos claridad

5. Pongo un ejemplo entre muchos: ninguna de las dos revistas mexicanas dedicadas a la música reúnen los requisitos de arbitraje, regularidad y distribución que son exigidos a los colegas de otras disciplinas afines que se publican en M éxico.

6. "T he Price of Literacy", frase tomada del artículo homónimo: "T he Price of Literacy, or, Why We N eed M usicology", en Richard Taruskin, Text \& Act, Essays on M usic and Performance, O xford University Press, 1995, pp. 344 y ss.

7. Ralph P. Locke, "M usicology and/as Social Concern", en N icholas Cook y M ark Everist (eds.), Rethinking M usic, O xford University Press, 2001, p. 503.

8. H arold Bloom, "Elegía al canon", en El canon occidental, la escuela y los libros de todas las épocas, Barcelona, Anagrama, 1994, p. 51. 
respecto al canon musical de $M$ éxico y que podremos entonces debatir acerca de sus razones y proponer alternativas, ${ }^{9}$ que en veinte años más los músicos relevantes de M éxico tendrán su obra editada y grabada; que en dos décadas la corrupción, la pobreza y el centralismo habrán desaparecido de la disciplina - si no del país entero- y que no habrá malentendidos ni abusos al definir quién es musicólogo y quién no lo es. Algo llamado realidad, sin embargo, hace recordar la expresión de abatimiento de Genaro Codina e imaginar, esta vez con el fundamento del estado actual de la disciplina, que el concierto musicológico local de tesituras encontradas habrá de proseguir in crescendo y ad infinitum.

9. No ignoro que la musicología ha debatido en términos recientes la importancia y la construcción del canon. Esa discusión, sin embargo, apenas podría emprenderse a propósito de la música mexicana en tanto no exista mayor crítica respecto a la creación musical de los autores mexicanos. Sobre las distintas críticas y cuestionamientos al canon y sobre la relevancia de éste para la práctica musicológica, véanse - además de los trabajos referidos en este ensayo"The H istory of M usical Canon" de W illiam Weber; "Reception Theories, C anonic D iscourses, and M usical Value", de M ark Everist, y "W hat do We Want to Teach When We Teach M usic?", de Ellen Koskoff, en Nicholas Cook y M ark Everist (eds.), Rethinking M usic, O xford University Press, 2001, así como el ensayo de Joseph Kerman, "A Few Canonic Variations", en Write all These D own, Essays on M usic, Berkeley, U niversity of California Press, 1994. 